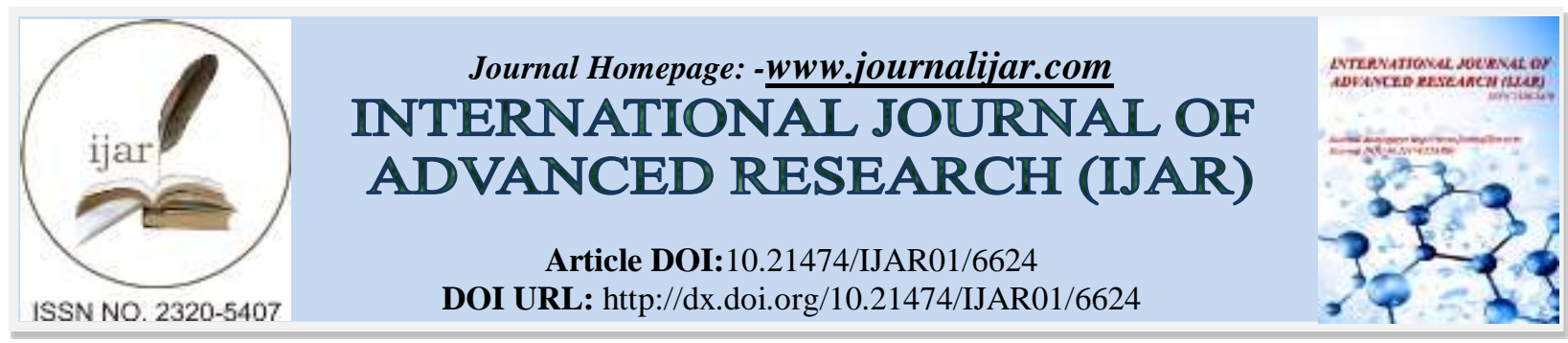

RESEARCH ARTICLE

\title{
EVALUATION OF THE LOCAL ANAESTHETIC EFFECT OF CRASSOCEPHALUM CREPIDIOIDES IN SUITABLE EXPERIMENTAL ANIMAL MODELS.
}

\author{
Ananya Das. \\ Post Graduate Trainee, Department of Pharmacology, RIMS, Imphal, Manipur.
}

\section{Manuscript Info}

Manuscript History

Received: 24 December 2017

Final Accepted: 26 January 2018

Published: February 2018

Keywords:-

Local anaesthesia, xylocaine,

\section{Abstract}

Objective: Crassocephalum crepidioides (Family: Asteraceae) is an errect, annual and succulent herb growing in many tropical regions. This plant has been used to treat indigestion, diarrhoea, headache and epilepsy by the local people. The leaves are heated and the succus is used for treating sores and fresh wounds since many years. Hence considering its use in treating wounds for many years by the local people in different parts of the world, an attempt has been made to evaluate the role of Crassocephalum crepidioides in local anaesthesia using suitable experimental animal models.

Materials and methods: Methanol extract of Crassocephalum crepidioides was tested for local anaesthetic action by using the following models: (i) intracutaneous wheal in guinea pigs (ii) plexus anaesthesia in frogs. In both the models $0.9 \%$ normal saline was used as a control and $2 \%$ xylocaine was used as the standard drug.

Results: The intracutaneous wheal method in guinea pigs showed $0.33 \%$ and $0.57 \%$ anaesthesia in test drug of concentrations of $10 \%$ and $20 \%$ respectively compared to $93.33 \%$ anaesthesia using the standard drug, xylocaine of $2 \%$ concentration $(\mathrm{P}<0.01)$. In the lumbar plexus anaesthesia method in frogs, the onset of local anaesthetic action was $5.12 \pm 0.14$ and $2.09 \pm 0.12 \mathrm{~min}$ in the test and xylocaine treated groups respectively when compared to the control group where it was $18.13 \pm 0.29 \min (\mathrm{P}<0.001)$.

Conclusion: The present study showed that Crassocephalum crepidioides has significant local anaesthetic property.

Copy Right, IJAR, 2018,. All rights reserved.

\section{Introduction:-}

Local anaesthetics (LA) are drugs which upon local injection or topical application cause reversible loss of sensory perception, especially that of pain, in a restricted area of the body. ${ }^{(1)}$ The basic mechanism of action of all LAs are that they interrupt neural conduction by inhibiting the influx of sodium ions through channels within the neuronal membranes. Normally these channels exist in a resting state, during which sodium ions are prevented from entering the cell. When the neuron is stimulated, the channel assumes an activated state, in which sodium ions diffuse into the cell, causing depolarization. Due to this sudden change in membrane voltage, the sodium channel assumes an inactivated state, during which further influx is inhibited while active transport mechanisms return sodium ions to 
the exterior. Following this repolarization, the channel assumes its normal resting state. Local anaesthetics have greater affinity for receptors within the sodium channels during their activated and inactivated states than when they are in their resting states. ${ }^{(2,3)}$ Therefore, neural fibres having more rapid firing rates are most susceptible to local anaesthetic action. Crassocephalum crepidioides (Family: Asteraceae) known as Thickhead in English and Terapaibi in Manipuri is an errect, annual and succulent herb growing in many tropical regions. The leaves are mainly used to treat indigestion, diarrhoea, headache and epilepsy by the local people. In Tanzania the dried leaf powder is applied as a snuff to stop nose bleeding and smoked to treat sleeping sickness. ${ }^{(4)}$ The leaves are heated and then the succus is used for sores and fresh wounds by the local people for many years. ${ }^{(5)}$ However, till date no scientific study has been encountered regarding the evaluation of the effect of the plant in local anaesthetic activity. Hence considering its use in treating wounds for many years by the local people in different parts of the world, an attempt was made to evaluate the role of Crassocephalum crepidioides (CC) in local anaesthesia using suitable experimental animal models.

\section{Materials and methods:-}

\section{Preparation of the methanol extract:-}

The leaves of CC were collected from the Imphal valley during the month of June-July and authenticated. They were washed, dried and powdered in a mixer grinder. Fifty grams of this powder was then extracted with methanol using a soxhlet apparatus. ${ }^{(6)}$ The extract was evaporated to dryness and the final yield was $14 \%$ which was stored in the refrigerator and fresh sterile solutions were prepared as and when required by dissolving it in normal saline.

\section{Phytochemical studies:-}

Freshly prepared methanol extract of Crassocephalum crepidioides (MECC) was subjected to phytochemical screening that revealed the presence of flavonoids, alkaloids, tannins and steroids. ${ }^{(7-10)}$

\section{Animals:-}

Adult guinea pigs (450-500 g) and frogs were procured from the Central Animal House of RIMS after taking approval from the Institutional Animal Ethics Committee (IAEC). The animals were kept at a controlled room temperature $\left(22 \pm 2^{0} \mathrm{C}\right.$; relative humidity $\left.60-70 \%\right)$ in a $12 \mathrm{~h}$ light-dark cycle. and housed for 1 week in separate polypropylene cages before the experiment to acclimatize to the laboratory conditions. They were given standard laboratory diet and water ad libitum.

\section{Acute toxicity testing:-}

It was found that the plant extract was safe up to a dose of $2 \mathrm{~g} / \mathrm{kg}$ of body weight p.o. during the $24 \mathrm{~h}$ observation period. ${ }^{(11)}$

\section{Study design:- \\ Intracutaneous wheal in guinea pigs:-}

The standard operating procedure for testing local anaesthesia as recommended by Bulbring and Wajda was followed in this present study. ${ }^{(12,13)}$ The animals were divided into four groups as seen in table 1 . On the day prior to the study, the hair on the back of guinea pigs near the midline (four different areas of $3 \mathrm{~cm}$ each) was shaved. The normal responses of the animals were observed first by applying pin pricks in the midline. The required drugs were then injected intracutaneously in equal volumes of $0.2 \mathrm{ml}$ into the shaved areas. The wheals were marked using a marker and the time of injection was noted. Five pin pricks were then given uniformly every five min at an interval of four seconds on the wheal areas. The responses were recorded up to a period of $30 \mathrm{~min}$. A localized skin twitch usually accompanied by squeak was considered as the normal response. A negative response was recorded when the animal failed to respond either by twitching of the muscle or squeaking following a pin prick.

\section{Plexus anaesthesia in frogs:-}

The frogs were divided into three groups as shown in table 2. The frogs were decerebrated and upper parts of their spinal cords were destroyed using a pithing needle. The abdominal viscera was completely excised and removed through a transverse incision made just below the sternum thereby forming a pouch. The lumbar plexus was exposed carefully without damaging it. The frogs were pinned to the vertical boards with their legs hanging down. The drugs were administered into the abdominal pouch in sufficient volumes to submerge the lumbar plexus. The left and right limbs of the frogs were immersed every minute for a maximum period of $10 \mathrm{sec}$ in beakers containing $0.1 \mathrm{~N} \mathrm{HCl}$ 
and normal saline respectively. Afterwards the feet were rinsed in water. The time taken by the animals failing to withdraw their feet was recorded as the "onset of local anaesthetic action."

Analysis of results:-

The data obtained in the studies was analysed using one way analysis of variance (ANOVA) followed by Dunnett's ' $t$ ' test. A 'P' value $<0.05$ was considered statistically significant.

\section{Results:-}

Table 1:- Local anaesthetic activity of MECC on intracutaneous wheal in guinea pigs

\begin{tabular}{|c|c|c|}
\hline Group & Drugs & No. of negative responses \\
\hline I (control) & $\mathbf{0 . 9 \%}$ saline & $\mathbf{0 . 3 3} \pm \mathbf{0 . 2 1} *$ \\
\hline II (standard) & $\mathbf{2 \%}$ xylocaine & $\mathbf{4 . 6 7 \pm 0 . 2 1} *$ \\
\hline III (test) & $\mathbf{1 0 \%}$ MECC & $\mathbf{1 . 6 7 \pm 0 . 2 1 *}$ \\
\hline IV (test) & $\mathbf{2 0 \%}$ MECC & $\mathbf{2 . 8 3} \pm \mathbf{0 . 1 7}$ \\
\hline & n=6 in all groups, *P<0.01 when compared to control \\
\hline
\end{tabular}

Table 2:- Local anaesthetic activity of MECC on plexus anaesthesia in frogs

\begin{tabular}{|c|c|c|}
\hline Groups & Drugs & $\begin{array}{c}\text { Onset of local } \\
\text { anaesthetic action(min) }\end{array}$ \\
\hline I (control) & $\mathbf{0 . 9 \%}$ saline & $\mathbf{1 8 . 1 3 \pm 0 . 2 9 *}$ \\
\hline II (standard) & $\mathbf{2 \%}$ xylocaine & $\mathbf{2 . 0 9 \pm 0 . 1 2 *}$ \\
\hline III (test) & $20 \%$ MECC & $5.12 \pm 0.14 *$ \\
\hline & n=6 in all groups, $* \mathbf{P}<0.001$ when compared to control \\
\hline
\end{tabular}

Bar diagram 1:- Local anaesthetic activity of MECC on intracutaneous wheal in guinea pigs

No. of negative responses

\subsection{7}

\subsection{3}

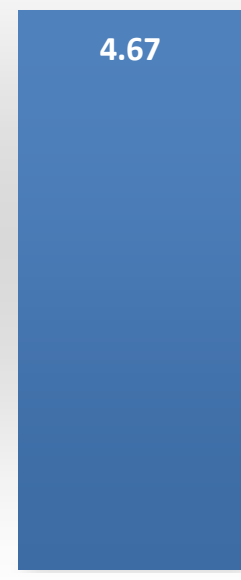

Group I

Group II

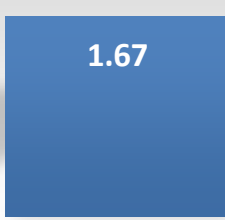

Group III

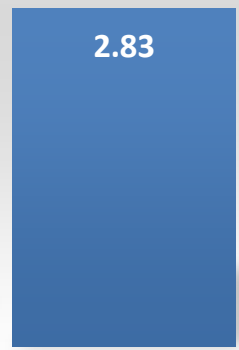

Group IV 
Bar diagram 2:- Local anaesthetic activity of MECC on plexus anaesthesia in frogs

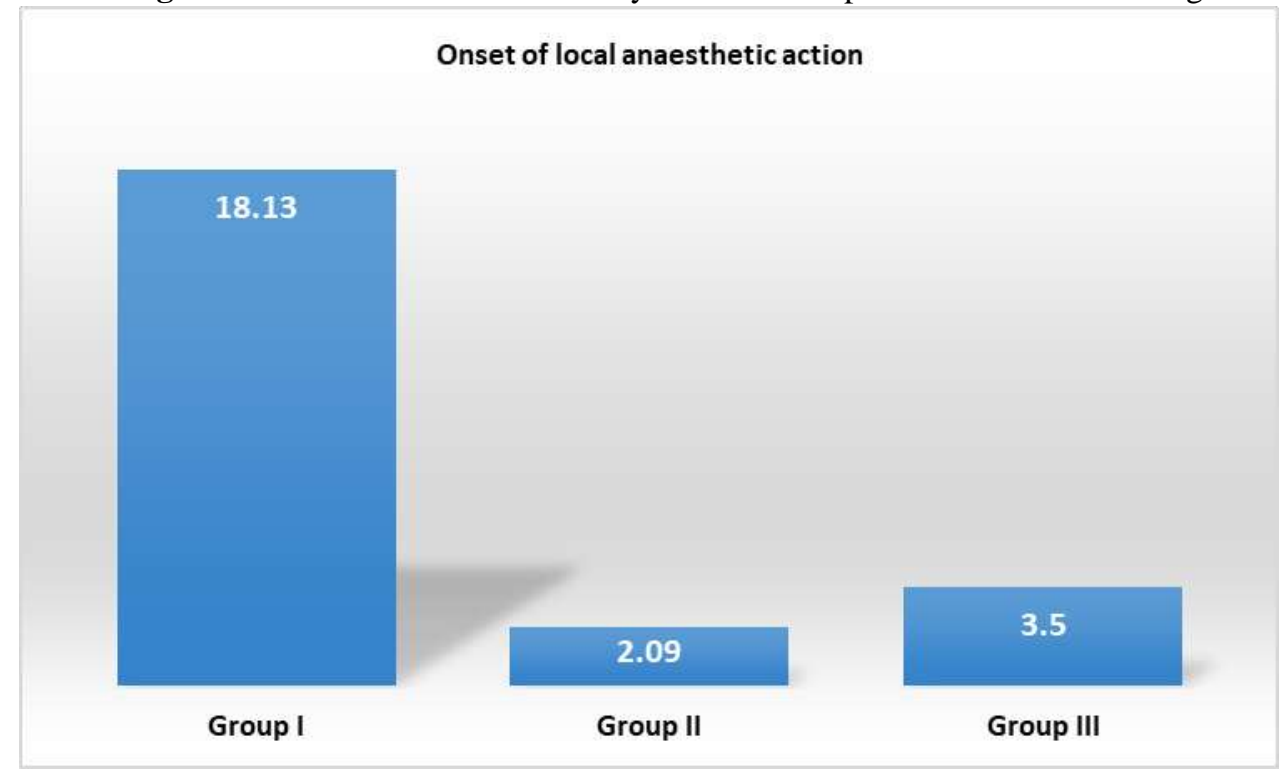

The intracutaneous wheal method in guinea pigs showed $0.33 \%$ and $0.57 \%$ anaesthesia in test drug of concentrations of $10 \%$ and $20 \%$ respectively compared to $93.33 \%$ anaesthesia using the standard drug, xylocaine of $2 \%$ concentration. The negative responses of the standard and the extract treated groups showed a significant increase $(\mathrm{P}<0.01)$ in the anaesthetic effect when compared to the control group.

In the lumbar plexus anaesthesia method in frogs, the onset of local anaesthetic action was $5.12 \pm 0.14$ and $2.09 \pm 0.12$ min in the test and xylocaine treated groups respectively when compared to the control group where it was $18.13 \pm 0.29 \mathrm{~min}$. The anaesthetic effect of the standard and test drugs continued till $30 \mathrm{~min}$ of our observation period.

\section{Discussion:-}

There is an increasing interest in finding herbal extracts with local anaesthetic activity for treating cuts and wounds which also has been used in traditional medicine in many parts of the world since ancient times. This study was planned as a preclinical trial to demonstrate the local anaesthetic activity of MECC. Guinea pigs maintained under standard conditions were given intracutaneous injection using different concentration of MECC and xylocaine for 30 min. Similarly, using the plexus anaesthesia model, the local anaesthetic effect was tested on frogs using $10 \%$ and $20 \%$ MECC and compared with the standard drug, xylocaine. It was found that the plant extracts showed significant local anaesthetic activity in both the models when compared to xylocaine. The wheal model used in guinea pigs was suitable in measuring the degree and duration of anaesthesia simultaneously whereas the plexus model determined the onset of anaesthesia. ${ }^{(16)}$ This property may be attributed to the phytoconstituent, alkaloid that is present in this plant.

Limitations of the study: Since the study was in preclinical phase, nonhuman subjects (guinea pigs and frogs) were used here.

\section{Conclusion:-}

The present study concluded that local anaesthetic activity of the MECC showed significant comparable activity with the standard and control which was used in the study. Hence, a new molecule with local anaesthetic activity similar to xylocaine can be developed as plant extracts may have higher margin of safety with minimum or no side effects.

\section{Financial support and sponsorship:- Nil}

Conflicts of interest:- There are no conflicts of interest. 


\section{References:-}

1. Tripathi KD. Essentials of Medical Pharmacology. 7th ed. New Delhi:Jaypee Brothers Medical Publishers (P) Ltd;2013. 377 p.

2. Berde CB, Strichartz GR. Local anaesthetics. In: Miller RD, Eriksson LI, Fleisher LA, et al, editors. Miller's Anaesthesia. 7th ed. Philadelphia, Pa: Elsevier, Churchill Livingstone; 2009.

3. Katzung BG, White PF. Local anaesthetics. In: Katzung BG, Masters SB, Trevor AJ, editors. Basic and Clinical Pharmacology. 11th ed. New York, NY: McGraw-Hill Companies Inc; 2009.

4. Musa AA, Adekomi DA, Tijani AA, Muhammed OA. Some of the effect of Crassocephalum crepidioides on the frontal cortex, kidney, liver and testis of adult male Sprague Dawley Rats: Microanatomical study. European Journal of Experimental Biology 2011;1(3):228-35.

5. Jorim RY, Korape S, Legu W, Koch M, Barrows LR, Matainaho TK, et al. An ethnobotanical survey of medicinal plants used in the eastern highlands of Papua New Guinea. J Ethnobiol Ethnomed2012;8:47-63.

6. Dhiman A, Nanda A, Ahmad S, Narasimhan B. In vitro antimicrobial activity of methanolic leaf extract of Psidium guajava L. J Pharm Bioallied Sci 2011;3(2):226-9.

7. Kumar U, Kumar B, Bhandari A, Kumar Y. Phytochemical investigation and comparison of antimicrobial screening of clove and cardamom. Int J Pharm Sci Res 2010;1(12):138-47.

8. Shah B, Seth AK. Textbook of pharmacognosy and phytochemistry. 2nd ed. New Delhi: Elsevier; 2014.

9. Dhanasekaran M, Abraham GC, Mohan S. Preliminary phytochemical and histochemical investigation on Kigelia pinnata DC. International Journal of Pharma Sciences and Research 2014;5(7):413-9.

10. Bargah RK. Preliminary test of phytochemical screening of crude ethanolic and aqueous extract of Moringa pterygosperma Gaertn. J Pharmacogn Phytochem 2015;4(1):7-9.

11. OECD iLibrary. OECD guidelines for the testing of chemicals, Section 4. Test no. 423: Acute Oral toxicity- Acute toxic class method. Available at: http://www.oecd-ilibrary.org/environment/test-no-423-acute-oral-toxicity-acutetoxic-class-method_9789264071001-en. Accessed August 16, 2015.

12. Bulbring E, Wajda I. Biological comparison of local anaesthetics. J Pharmacol Exp Ther. 1945;85:78-84.

13. Gerald Vogel H. Effect of peripheral nerve function. In: Gerald Vogel H, Bernward A, editors. Drug Discovery and Evaluation- Pharmacological Assay. 2nd ed. Heidelberg: Springer; 2008. p. 957.

14. Boruah RN, Leclercq PA. Characterisation of the essential oil from flower heads of Spilanthes acmella. J Essential Oil Res 5;1993:693-5.

15. Liu SS, Michel AA, Linda JR. The management of pain, Churchill living stone inc, USA 1998:447-8.

16. Agshikar NV, Abraham G J. Pharmacology and acute toxicity of essential oil extracted from Zanthoxylum budrunga. Indian J med Res. 60;1972:757-61. 